\title{
Poverty, Road Culture and Deviance among Areaboys in Lagos Central Neighbourhood
}

\author{
Ikuomola Adediran Daniel
}

Department of Sociology, Adekunle Ajasin University, Akungba-Akoko, Nigeria

\begin{abstract}
The role and importance of poverty within the youth subculture ('road' life) of young areaboys growing up in Lagos Central Neighbourhood cannot be overemphasised. This research explores how the notion of poverty particularly influences touts attitudes, values, behaviour and lifestyle; the way in which the majority of young touts involved with road life, look to appropriate and flirt with certain aspects of deviance for reasons to do with survival, 'money-making', and aesthetics (style and fashion). This paper is based upon a much larger ethnographic study undertaken in Lagos State transportation corridors (Surulere and Lagos Island Local government areas), it adopts and integrates the concepts of 'drift' (Matza, 1964), 'code of the street' (Anderson, 1999), and the 'seductions of crime' (Katz, 1988) in the analysis and discussion of the findings. Empirical data was gleaned via participant observation supplemented by semi-structured interviews among a cross section of 120 respondents. This study revealed that touts are filling a gap in service along the transportation corridors and the touting vocation is more attractive to migrant-unemployed and unskilled youths. This is more so for individuals with difficult childhood, resulting from familial, psychological and socioeconomic challenges. It is therefore recommended that government and organised private sector should prioritise and intensify skill acquisition programmes; job creation and reformation of neighbourhoods along transportation corridors to reduce the image problems in the heart of Lagos state.
\end{abstract}

Keywords Poverty, Survival, Areaboys, Transportation Corridors

\section{Introduction}

Male youths along the transportation corridors in Nigeria as a problem' question looms large both within the academy and the news - media, particularly in relation to street crime, and educational underachievement. When looking at the indices of social alienation and discrimination, it is likely that they will constitute quite a number that detail poverty, mental illness, school exclusions, educational underachievement and criminal conviction rates (Okunola, 2009; Ikuomola, 2010). For some commentators, poverty and institutionalized neglect are still the root causes for this continued social marginalization. In contrast, other writers play down such 'politically correct' interpretations, preferring to place the blame on male youth culture that is anti-school and obsessed with the violence and hyper-masculinity of the street (Owumi, 1997, Sewell, 1997). However, both positions tend to stereotype all young males as belonging to a larger homogenous collective. In truth, there is a dearth of empirical research - rooted within local neighbourhood settings - that attempts to explore many of the complexities and differences inherent within the contemporary La

* Corresponding author:

diranreal@yahoo.com (Ikuomola Adediran Daniel)

Published online at http://journal.sapub.org/ijpt

Copyright (C) 2012 Scientific \& Academic Publishing. All Rights Reserved gos-street youth experience(s). The generally social analysis around particular people be it the poor, ethnic minorities, has been dominated by macro theorizing that has highlighted the systematic essence of discrimination as evidenced through structural inequality and social exclusion.

However, the downside of this is illustrated by policy makers and the academy's failure to understand the role of human agency in the making of individuals, and our versions of individual making are empty and mechanistic assertions about the social and political underpinning of the poor, which are not substantiated with truth (Knowles, 2003). Indeed when looking specifically at research exploring poverty, deviance, offending and victimization within neighbourhoods, Garland et al. (2006: 423) similarly note that 'there has been a tendency within this work to make sweeping assumptions' about those groups that fall under the broad 'catch-all' 'poor' and 'deviance' categories often referred to in academic and official government agency reports. Phillips and Bowling (2003) also point out that criminologists interested in street youths have tended to view the disproportionate numbers of the poor individuals caught up within the criminal justice system as being either symptomatic of their higher rates of offending or because of institutionalized neglect. The suggested alternative to the above 'either/or' youth deviance conundrum is the development of 'minority perspectives' within the field of criminology that might contribute to a more multidimen- 
sional approach to understanding touts' experience of victimisation, offending, [and] criminal justice processing.

This paper will therefore attempt to give voice to its young touts subjects' particular perspectives, it nevertheless confronts the thorny 'criminological issue' that is youth and crime and the wider political and ideological implications. The question that remains, particularly for this, is how to undertake empirical research with street/area boys popular referred to as 'tout' subjects that avoids the creation of 'false pathologies' that uphold age-old stereotypes and stigma attached to them like that of the Europeans against the black criminal 'other' (Keith, 1993). Even taking into account the development of 'minority perspectives' within criminological research by examining localized/ individualized identities and histories as understood through the broader macro social and political apparatus (Spalek, 2008), does not necessarily ensure against those neighbourhood that are placed under the research lens becoming 'otherised'. This paper by 'highlighting the specific cultural contexts to deviance, crime and victimization' of its Lagos male subjects (touts) will contribute further to issues relating to touting in the Nigerian transportation corridors.

My concluding arguments with regard to this problem echo that of Owumi, (1994) and Isamah and Okunola, (1997), in that, notwithstanding the potential political fallout from empirical and theoretical research around poverty, touts, road culture, and crime, 'there is still much to be learned and there remains a potential for both social good and harm in examining this controversial and difficult subject'. It is a fact that some touts do become involved in crime whereby they are then disproportionately punished by the state as demonstrated by their over-representation within all areas of the criminal justice system in Lagos central neighbourhood (LCN) (Iginla, 2007; Ikuomola, 2010). It is important therefore to explore why these individuals become involved in deviance and crime. By failing to explore the offending behaviour of some individuals, Hallsworth (2005: 89) maintains that neighbourhood themselves are being 'dealt a disservice by those who claim to represent them'.

\section{The Research}

This paper draws on data derived from a larger ethnographic youth study undertaken in the street of Surulere, (Shitta, Bode Thomas, Ijesha-tedo), Lagos Island (Idumota, CMS, Broad street, and Bar beach), all situated in Lagos Central Neighbourhood (Senatorial District). According to the 2007 Lagos state judiciary report data, LCN has the highest number of touts and street children population, with almost one-third of its residents coming from other communities within and outside the State: Yoruba, non-Yoruba and other West African neighbours. LC is also a neighbourhood that scores highly on all 'official' agency (index of Local Conditions) indices that measure social and economic deprivation (Iginla, 2007). The majority of the 120 respon- dents featured in this study were Yoruba males (82\%), with the remainder of the research sample comprising of non Yoruba (11\%), Togolese (2\%) and Bennenoise (5\%) males. The research entailed my directly observing and engaging with the informants in a variety of settings - the motor parks, bus stops, drinking joints (bar) beach, on the streets, and residentials out of town. In addition, I carried out semistructured tape-recorded interviews with 52 young people, all males. The ages of all the young respondents featured in the study ranged from $11-25$. The research period spanned a period of 9 months; however, I was familiar with some of the young people and the research site as I had course to work and visit friends and family in LCN about seven years prior to the study as an advertisement practitioner.

Within this paper I am particularly concerned with detailing and exploring the role and impact of deviance (via the youth sub culture) upon the attitudes, values and behavior of young male-touts living in LCN. In this paper I attempt to move beyond macro theorizing about the youth problem by applying Matza's (1964) very much neglected notion of drift - which I integrate with the code of the street (Anderson, 1999) and seduction of crime (Katz, 1988, as updated and continued within the area of cultural criminology, see Young, 2003; Ferrell et al., 2004) perspectives - to my own empirical research findings. In so doing, this paper will attempt to demonstrate how personality/neighbourhood, socio-economic status, residential locality and the aesthetics and pleasures associated with deviance combine at a micro level and thus provide the backcloth for the individualized behavioural and lifestyle choices made by young male-touts living in LC neighbourhood.

\section{Road Culture}

Within this paper 'Road culture' (or 'Road life', as termed by the young people themselves) is viewed as a continuum, where occupying the centre ground are the vast majority of non-spectacular young people, with a small minority of young males or 'rude boys' - who immerse themselves into the world of deviance - taking up the extreme margins. Deviance (as defined by the informants within this study) refers to a social world characterized by 'spectacular' hyper aggressive/hyper masculine modes of behaviour, incorporating violent and petty crime, fraud/personal identity theft and low-level drug dealing. Of course there are a small number of young males who continually travel back and forth between the centre and the margins of Road culture. In essence, Road life is not about the margins at all; its life force is derived from the majority of young people who make up its centre ground. For the majority of young touts males in LC, Road life is not about rebellion or hedonism, rather it is centred upon meeting up with friends, 'hanging on Road', attending the youth gang, raving, looking 'links' and 'catching joke'. In essence, Road life is about friendships, routine and the familiar (Gunter, 2004; Ikuomola, 2010) or doing nothing (Corrigan, 1979). 
Road life in LCN and the surrounding neighbourhoods as is the case with larger number of touts in other parts of Lagos Island and Mainland, youth subcultures - is largely influenced by expressive musical (emphasis on fuji music) and diasporic popular cultures in terms of dressing (Ikuomola, 2010). Fuji and hip-hop musicians are the principal internal cultural driving forces of LC youth subculture(s) via the speech styles. America and British influence serve as external cultural driving forces on dress wear and attitudes associated with the western popular music forms of bashment and hip-hop. Both these musical forms have successfully managed to convey, through song lyrics, the significance and general acceptance of 'deviance-honour' which according to Obika Gray is an oral kinetic practice in Jamaica that employs a repertoire of violent and intimidating language, physical gestures and actions that 'enables claimants, usually from disadvantaged groups, to secure ... a modicum of power and respect' (Gray, 2003: 18) - and the perennial appeal of the 'bad ass', the 'bad nigger' and the 'rude boy' within the ghettos and poor neighbourhoods of Jamaica and black America (Van Deburg, 2004). The rough and hip image of popular musicians and big-time transport union members (NURTW and RTEAN) similar to the black outlaw within black popular culture holds a strong appeal amongst a small number of the young touts males who lived in LC and 'practised deviance' - within this paper, I refer to these young males as 'rude boys'. For the small number of young men who practised deviance, being a criminal was viewed negatively and there were no kudos or value attached to such a term. In contrast, however, a rude boy or 'ghetto don' is about power, as it entails having the entire neighbourhood 'fear you', 'look up to you' or 'aspire to be like you'.

The Road cultural style and fashion (as adopted by the majority of black male youth) is very much influenced by the hyper-masculine and style conscious attitudes and personas of the rude boys depicted in American and Jamaican films. Therefore, the majority of young males involved in Road life will tend to walk around in small groups, wearing designer sportswear (Nike sportswear is the brand of choice, followed by Adidas and then Reebok): hooded sports tops and jackets (normally with hood up, even in blazing sunshine), baseball caps, tracksuit bottoms or straight-legged designer trousers or denim jeans. To get the straight-legged effect, the trousers or jeans are taken in from just below the knee right down to the ankles to give a drainpipe effect. Designer labels of choice for trousers, jeans and shirts are Versace, Valentino, Stone Island, Iceberg, Armani and Moschino. When walking, these young touts will look to 'hog the pavement' (thus making it difficult for other members of the public to pass by without having to step into the Road) by walking in small groups oblivious to other pavement-users' needs. They also will adopt a 'screw face' (described at best as a blank expression, at worst as hostile and aggressive) in order to warn potential male foes that they are 'not to be messed with'. In short, these young males are putting out a message that they are not victims (weak or 'pussies'), rather they are the victimizers. Unfortunately, to the outside world these young males are indistinguishable from 'rude boys' in the street of London and Jamaica (Gunter, 2008) There are a good number of touts who feel slighted at being wrongly stereotyped as being rude, aggressive and truculent:

Paparazi: Seeing me (stocky young male) my rugged jeans, cap and singlet and posing around the beach and because of the way I talk to people, my hairdo and my dressing style, they think I am ruffian, and the look $i$ their eyes is like I am probably going to rub them soonest. The public gets a wrong impression of whom I am, all what is in their mind is that I am a touts, a drug addict, they just judge us without coming closer to know who we are

\section{Safety in LC Neighbourhoods}

Many of the informants (as well as their parents) were born in the area - or very near to it - and had built up extensive local kinship, family and friendship networks. This was important for engendering a strong local identification and helped with regard to feelings of 'safety' within their own neighbourhood. Whilst it was acknowledged that LC was a 'rough' area, for some of those young people who lived there it was a 'safe area', perhaps because they were related to, or friendly with, those individuals who contributed to the notoriety of the area:

Linky: I am at home here, there is problem what so ever, nobody can give us any shit (yawa). LC is my life my Life is $\mathrm{LC}$, there is no one on this Island especially Isale eko that does not know me or my elder brothers (notoriously rude guys who once terrorised the neighbourhood) and that is how I live, I fear no trouble

Flexxy: Sometimes if one steps outside the boundary of one's gang, it may not be funny, but the good time is that my guys will fight back latter. The good thing is that if one knows that a particular area is ful of bad boys and you grew up among them be it thieves or areaboys then you don't need to fear, you are not in any danger because we are all prepared. But if you are a person who has just come to the area and you do not know the area, the guys, and you do not know the whatever else, then to you it's dangerous.

Sexxy: for me there is no problem, we are always comfortable with our area.

Elewe: we are all security ourselves we secure the area, forget the police we run things all day and night, even the police know this we give them what they want, and we get what we want. No barrier.

Yet not all of the young informants felt 'safe' in LC. Those who did not have local family or peer support networks to call upon - and/or were perceived as 'weak' as opposed to being tough and street-smart - were vulnerable on the streets to bullying, robbery and violence by their more dominant peers. 


\section{Deviance, Drift and the Code of the Street}

The majority of young touts involved in Road life within LC occupied the centre ground, with a small minority (rude boys) taking up the extreme margins. There was, however, a great deal of fluidity and movement between the centre ground and the margins, by a sizeable number of young males. At some point or another those young males who normally occupy the centre ground of Road culture will intermittently become embroiled within the world of deviance, being bad, perhaps through their associations (friendly and antagonistic) with rude boys, or as a result of 'drift' (Matza, 1964), where these young males' involvement in deviant and criminal activity is both transient and sporadic.

Adapting Matza's notion of 'drift', I would argue that the majority of touts in LC were neither committed to the values of the non-conformist areaboys or gangs, nor to those of mainstream society. Consequently, many of those young males who normally occupied the centre ground also sometimes chose to dip in and out of deviance (or criminal activity) as and when they saw fit, or more to the point, when a particularly good opportunity arose for them to make some 'easy money'. The types of criminal activity the majority of young males tended to get involved with centred around the buying (purchasing - or acting as middlemen) of stolen goods from older touts acquaintances, friends and family members and selling stolen goods like designer wrist watches, shoes, clothing, Sony Play Stations, car radios and DVD players and drugs especially Indian helms (marijuana) and Chinese capsules. The elderly ones among them (older touts) usually at the background involve in money-making scams - such as receiving commission for the successful 'street sale' of a 'hot' mobile phone from the boys who actually stole it. This explains the way in which certain groups of young people can become involved within the informal labour market on the edges of crime (Isamah and Okunola, 1997; Okojie, 2003).

As noted earlier in this paper, many of the young touts involved in Road culture in LC felt compelled to adopt and take on rude boy aesthetics and posturing as popular Jamaican film (third world cops) portrays, as a means of negotiating their own 'safe' path through the potential dangers of hyper-masculinist neighbourhood life. Consequently, the non-rude boy's involvement in deviance might also arise as a result of a 'beef' - here denoting a dispute or argument with another young man or crew; at such times it is imperative that all parties involved are willing to 'back it' and bring the dispute to a violent conclusion. Unfortunately, the violent conclusion will ordinarily involve knives or other weapons and more than likely result with one crew or group of young males ('backing' their mate) rushing (violently assaulting) an individual or smaller group of young males. Street logic - or what Anderson (1999) refers to as the code of the street - further dictates that if a young male seemingly fails to adequately 'back' or 'quash' (resolve the dispute through the threat of physical violence) any of his disputes as and when they arise, he will subsequently be labelled a 'smally' and from there on he will lose his 'rep' and be subject to constant bullying and harassment. One evening at the beach, one of my informants in CMS, Iron rod, came bursting from the bridge and the following conversation ensued with his group:

Iron rod: Some boys are not as strong as you think, any small swerve they are off and their dick runs inside, however one is not to take them for granted, as tomorrow they may regroup and face us again.

Constance: Give us our share! I say give us our Own! We heard that you just smashed a boy! It's like there you had a good sale across?

Iron rod: It is that new boy who calls himself 'King', I saw him in the garage early this morning with two other small boys at the our section in the park eating fish 'smoking helm' without our permission, so I swerved him as he was about to run, I held him and took his wristwatch.

SevenUp: Thats nice at least after flinging the wristwatch before the day runs out we will have a good time at night, if not suya, (Smoked meat) we shall kaya (meaning to smoke marijuana)

Silencer: remember the watch will not just go like that, will still have to be prepared for fight from now on all of you should watch your movement from now on. None of you should let this group down. He warned them all.

Iron rod: For sure 'My Oga' I will do as you say.

Constance: All language decoded.

Seven up: demonstrated with some signs (I guess meant he concur)

Silencer: nodded his head and crossed his legs in response

Every other boys left the scene.

The life of growing touts is usually full of deviance, troubles and street smart to earning a living as a result of their poor background, poor parentage, with or/and without schooling, some other times from a middle class background. This to a large extend enabled the children within the neighbourhood to learn and be used to the various signs and symbols, coded slangs, for violence. This culture was described by an elderly man in the island as a culture that came about the area at the return of Boma boys, in 1940s from Sierra Leone (See, Heap, 2010). Similarly according to Stolzoff in his ethnographic study of Jamaican Dance Hall culture describes how young males from a ghetto neighbourhood in Kingston, Jamaica:

tended to romanticize those who were victimizers rather than victims. Ricky Trooper told me [you can't make a man kill you.] Being an innocent victim is one of the deepest fears of a ghetto youth man. (Stolzoff, 2000: 138)

Likewise young touts in LCN preferred to ally themselves with the perceived neighbourhood 'winners' (oppressors) as opposed to its 'losers' or 'smally' and 'fathead' - the term 'fathead' is used to denote those individuals who are viewed as weak and are therefore susceptible to being bullied and robbed by their more street-smart peers -whilst at the same time privately condemning and keeping at a safe, but friendly, distance from those Oppressors to whom they were not related or 'tight' (denoting a close friendship or 
alliance) with. Within the social world of LCN, familial and peer group attachments are essential for young people in terms of 'back up' and the possible retribution for an act of bullying, violence and robbery. As such, when a group of boys from LCN 'rush' or 'jack' a young person - either from LC or a surrounding neighbourhood - with no obvious familial or peer group attachments, most young males in public will just shrug their shoulders as if to say 'well that's just how things are on Road'. However, in private the young males will acknowledge that those (LCN 'oppressive boys') involved were 'out of order', they shouldn't have picked on an innocent. Yet the code of the street dictates that sympathy for the victim is at best fleeting and generally non-sympathetic, as the commonly held view amongst young males is that 'they' (victim) should not have allowed themselves to be 'swerved off just like that'. On the other hand, when the LC 'Oppressors', 'jack' or 'rush' a 'known' but disliked young person - usually a tout who does not play by the rules as determined within the world of being bad (perhaps they are 'jacking' young people indiscriminately, harassing young girls at corners of the roads and therefore creating lots of potential enemies within the neighbourhood) - the code of the street determines that the 'fathead' probably got what he deserved, as he was beginning to believe too much 'in his own hype', running about upsetting 'too many of the areaboys' in the neighbourhood.

In the ethnographic study of interpersonal violence between and among inner city African-American youths, Anderson (1999) argues, that in some seriously economically deprived, drug and crime ridden urban areas the rules of civil law are replaced by a code of the street:

At the heart of this code is a set of ... informal rules, of behaviour organised around a desperate search for respect that governs public social relations, especially violence among so many residents, particularly among young men and women. Possession of respect - and the credible threat of vengeance - is highly valued for shielding the ordinary person from the interpersonal violence of the street. (pp. 9-10).

Within this study, the rules of civil law do still patently exist within LCN among both its older and younger residents, touts and non touts. However, Matza's argument on delinquency and drift does allow for a more precise interpretation of the way in which the code of the street is operationalized within a diverse-ethnic neighbourhood of indigenes and settlers. It is important to point out that whilst 'drift' demonstrated the non-committal attitude toward badness on the part of the majority of the street boys in this study, their involvement on the periphery of deviance is nevertheless problematic in that they are, in comparison to other ethnic groupings (non-Yoruba and non-residents on the in the neighbourhood), more likely to be targeted by the police and other authorities during their drift between the poles of conformity and deviance. More worryingly, such young males, once caught up within the criminal justice process, are less likely to be protected by parents and other adult guardians who live far away from LCN or at most poor itinerant traders and more likely to be dealt with harshly by the police and courts (Stenson and Factor, 1994; Iginla, 2007). This in turn may reinforce the commitment to deviance of areaboys (young males) who only flirted on Lagos city periphery for their daily bread.

\section{Area Boys Stereotypes and Deviant Practices}

Many of the young people (featured in this study) as well as the wider society have internalised the media representations of 'bad dangerous and guys' (Owumi, 1994; Omitoogun, 1996; The Guardian. 2009). Whilst most touts, especially among the young ones are offended at such negative stereotypes and portrayals, there are a small number of informants who for their own personal reasons readily buy into those images of the 'cool' but 'dangerous' areaboy' urban rebel'. Whereas those of a more 'respectable' disposition refer to themselves as Omo A'dugbo (Homegrown children of the neighbourhood), which connote a different meaning, from Omoita (areaboys). According to Anderson (1999), the concept of decent street youth - might look to disassociate themselves from the negative representations of deviant and lawless youths (areaboys). For some who live and work as appendages with National Union of Road Transport Workers (NURTW) in CMS central Motor Park, they narrated their ordeal as residents in LC:

Shaky: The most shameful aspect of street life, the job in the park, and living in this area is the disrespect given to us, sometimes by our family members; by the various names we are called: Agbero, omo-ita touts, areaboys, while others do call us thieves. Agreed that we are touts, that does not mean we criminals; most times the police also arrest us incessantly, whenever there are reports of crime around neighbourhoods where we are stationed.

Oju'ina: there is no name they have not called us! The names keep changing, we still remain who we are children of the neighborhood, hustler to the core, born poor, but we have vowed not to remain poor, we will work if there are jobs to do, and if the money is right. If not we will keep hustling in this neighborhood.

Lekinsin: There are a lot of problems attached to this job, I cannot say which one is affecting us the most, but as an individual I get fed up when people think I am lazy and at the same time have this feeling that what I am doing is not a job. If only they know what it takes to go after molue and danfo, conductors and drivers, from morning till night everyday under the rain and sun, then they will appreciate us. We need to work and earn a living, that we know, but a lot of people outside think we should be doing some other things or jobs which are not there. Yet some of us who earn our daily bread in parks and bus stops without stealing are viewed as lazy.

Similarly there are many young areaboys (many of whom might from time-to-time flirt with certain money-making aspects of deviance) who are less condemning and judgemental of being deviants:

JJ: I do not think there is anything bad smoking Indian 
helm or cigarettes. I may look small, but my head can carry what some big guys may not be able to carry (referring to the quantity of Indian helm he smokes per wrap). It is not by size my brother! You will not believe I have being smoking for the past five years, when I was twelve after I left primary school....You look surprised...... don't worry it is a common thing around this area....take a walk at night or very early in the morning, under the bridge there are younger boys there... but one thing i donot involve myself is hard drugs such as cocaine and heroine, Chinese capsules, but I can easily give a link on how you can go about it if you need it.

Don Simon: here is nothing bad being on the road daily. It is far better than armed robbery. Some of my friends: Bingo, Salo, Jalo, and Loco are no more today because they were involved in an arm robbery operations two years ago. Since then I have told myself i rather die on the street hustling around parks and bus stops rather than being brought down by the gun of the Nigerian government.

Of course there are a minority of rude boys who gain kudos and pride from their (or their friends') various illegal and violent activities being featured in the crime pages of the local newspapers and thus adding further to their 'rep' as a 'macho' outlaw or up-and-coming gangster. The majority of deviance that takes place within LC and similar environs is carried out by a small number of young males (or gangs) who live above their income from the street, a lifestyle characterised with the daily patronage of pub, prostitutes and drinks. In the eventuality of running out of cash, these young touts are propelled to get involved in: property offences, which here incorporates theft from a house or shop and the taking and driving/riding away of a car or bike without the owner's consent; shoplifting, pick pocketing, fraud, to include selling or using a stolen cheque book, credit or other bank card to obtain money from a bank or to purchase items; violent offences, snatch from a person a purse, mobile phone, bag, jewellery or other possessions, to hurt someone with a knife, stick or weapon, or beat up someone especially at night, to such an extent that medical help is required. (The above are categories of offences as included in the 1994 Urban Violence Survey, see Albert, et. al. 1994). In addition to the above offences, street boys might also become involved in low-level drug dealing, operating on the bottom rung of the drug supply ladder selling small amounts of crack cocaine, marijuana and heroin (Owumi, 1994; Omitoogun, 1996).

There were some known gangs terrorising the Isale-Eko and Stadium/Barrack, axis of LC., The most identifiable and notorious perpetuators of deviant acts such as rape, mobile phone snatching and pocket picking in these areas are the Kainkain gangs (Isale-eko); Ice cube fraternity popularly known as Ice frat along Surulere, and Slimsthese are loose collective of young males touts, described by my informants as comprising of secondary school dropouts, children from broken homes, aged 17-21, in their numbers. The gang leader of the Kainkain group 'Surutu' was said to have been shot and has not been seen for some- time in the neighbourhood. Another significant perpetuator of rape in Surulere was a 21-year-old boy nicknamed 'lethim-go', who operated his own little crew of young bad boys. He had been chased out of the neighbourhood by the Landlord associations, after he was accused of raping a younger wife of one of the landlords, rumour has it that families of his former victims (in the island where his parents are) have cast a spell on him that keeps pushing him into committing rape. Slims are group of three boys expelled from the same school after ganging to beat-up a popular mathematics teacher nicknamed 'algebra' who caught one of them cheating in the examination hall four years before this study was conducted. In their possession was a knife and wrapped black substance suspected to be charm. Since then, their exclusion from school only helped propel them even further into a life of drug taking and selling (marijuana and Chinese capsule), violence and robbery. They are renowned in the neighbourhood and its surrounds for undertaking violent robberies and threatening violence to any person who got in his way, regardless of their age or reputation.

From the rumour mill and key informants, it was also said that these group of touts are linked to some criminal operations between Surulere up to Lagos Island, where most of their stolen wares are fling (sold). The group of boys (before the recent security measures put in place by Lagos the state government) were mostly concerned with fighting other young males in opposition to their conduct, from one street to another to uphold their dominant position within the neighbourhood, hustling and various 'moneymaking scams' usually involving fraud as well as opportunistic bullying and street robbery.

Street Harassment/Theft

The term 'street theft' is used within this paper to mean robbery or attempted robbery of personal property and snatch thefts on streets or in public settings, where victims are subjected to actual physical violence or threatened with physical violence. Though the true extent of street robbery offences cannot be ascertained, fascinatingly there are a good number of individuals who view street crime, assault and street theft as one and the same thing. It is however (like the true extent of street theft) also difficult to assess or measure the scale of the problem, as the majority of police forces within neighbourhood like every other state in Nigeria do not have updated statistics in relation to street theft offences. Official statistics for robbery offences in Nigeria rose sharply particularly during the late 1990s and early part of this decade (see Okunola, 2009). These increases were primarily attributed to the growing problem of 'street crime', used by some police forces to describe personal robbery and snatch thefts. However, it is one of those categories of crime about which the general public feels most apprehensive. Various research studies drawing upon official statistics and victim surveys have highlighted the over- representation of youths as street robbery suspects (Adisa, 1997; Okunola, 2009). However, as with the extrapolation of all crime statistics, data pertaining to touts profile of street 
robbery suspects needs to be treated with extreme caution as the 'available tout population within an area might not reflect the true nature of crime in the neighbourhood. Nevertheless, whilst acknowledging the shortcomings of research based upon official crime statistics, Harrington and Mayhew's (2001) study exploring mobile phone theft does highlight a number of issues that reverberate within the research, notably in explaining why street crime such as pick pocketing and mobile phones snatching are on the increase, apart from the key fact that they are small and valuable commodities with readymade resale markets, they also touch on a notion that phones are stolen in the process of 'taxing'. Here, the phone theft per se is less important than groups of offenders exerting control, establishing territorial rights and showing 'who's who' by penalising street users [in particular young ones] through phone theft amongst other things.

This issue of 'taxing' or 'flinging' is of great significance within LCN as it is the means by which many of the young boys police the physical space of the neighbourhood by exercising control and dominance, particularly over their more vulnerable male peers. Most harassment and stealing is opportunistic and might easily be described as 'street bullying' and does fit into what I described as a the common-sense image of young street areaboys taking to offence in order to fund an increasingly expensive lifestyle centered around acquiring the latest designer 'street wear' fashions. Sanders' (2005) study of black, white and 'mixed-race' young offenders in a South London inner-city borough similarly concludes that:

those more involved primarily committed serious acquisitive offences, such as robbery and burglary, with the intention of exchanging the stolen goods for cash ... The money these young people earned from such offences went towards status enhancing items and activities they enjoy, such as 'looking good', eating out, smoking cannabis, and raving ... (p. 75)

Many of the young boys featured in this research do not solely practice deviance as a means of obtaining the paraphernalia of 'style'. For young males such as my key respondents and informants Shanky and JJ, deviance entails maintaining and enhancing bad boy reputations and levels of respect (through the bullying and intimidation of new migrants and other young males) among their peers within the neighbourhood and its surrounds:

Shanky: if the new entrant are not swerved, it means we boys are not in control, they are expected to pay some money or join us to run things... we watch carefully too, to avoid other street boys from snatching them away from us, as well as protecting them. If this happens it is a lost on our part, so we act faster than other street guys. Once we settle with them we also protect them and their younger ones (Certainly for bar (money).

For JJ: he arrival of new families in the area is an avenue to make money. We assist them in off-loading their properties and they pay us some money that is a cool way of get- ting to know their worth and earning some kushie (money). Theorizing Deviance

Contemporary criminological explanations of the causes of crime (or aspects of deviance) - whilst not ignoring the many complex and subtly differentiated discourses around youth and crime present within criminology - have tended to focus on the pathology and cycles of deprivation/ amorality inherent within those cultures of the underclass (Alemika, 1997 Aderinto, 1997; Isamah and Okunola, 1997). Alternatively, they are reliant upon structural determinist interpretations of crime via the concept of relative deprivation) and draw upon liberal theories of delinquent youth subcultural formation (Cohen, 1955). Both perspectives or 'realist' Criminology concentrate more on those crimes which are at the centre of public concern, namely youth crime, street crime, violence and burglary, than of crimes of the powerful or those crimes perpetuated by the state itself. For 'realists' such as Lea and Young (1984), youth are pushed into the margins of society (and into a life of crime and relative deprivation) as a result of their family and self access to the labour market being denied via capitalism. In response to their exclusion from the social, economic and political institutions of mainstream society, a large number youth have transiently and other times as a career long affair created a criminal subcultures as a means of 'getting back' at the dominant culture. At the same time while strongly disagreeing with the notion of 'criminal' subcultures, critical cultural theorists of youth and crime (Gilroy, 1982; Gray, 2003; Sanders, 2005) argue that youths are unfairly labelled by the media and the neighbourhood which the belong as criminals and then actually turned into criminals by the criminal justice system as a result of institutionalized poverty. Interestingly, whilst left realists look to blame changes in the globalized capitalist and political economy for the creation of criminal youth subcultures, critical theorists argue that 'poverty and criminalization are not ends in themselves, but the result of a specific crisis in the capitalist economy (Phillips and. Bowling 2003). Other more notable additions to the youth crime debate draw on those discourses around hegemonic 'masculinity' (Connell, 1987), whereby class and position combine to place certain young males at the bottom of the social and economic ladder. As a response to such marginalization, areaboys in Lagos and other working class young males respond to their powerlessness by constructing subcultures based around crime and other deviant modes of behaviour (Ikuomola, et al. 2009). Again, the inference here is that such 'maverick' masculinities based upon deviance and criminality are in the main still largely determined by structural crises within the capitalist global and political economy creating the urban poor.

In a similar study on black youths in East London it was observed that deviance and acting bad is a lifestyle choice involving the complex interplay of power and control (via physical force), language, music, dress wear and a youthful disregard for the values and institutions of mainstream adult 
society - that is adopted by a small minority of male youths and is appropriated in a cut ' $\mathrm{n}$ ' mix style by even larger numbers of young people (Gunter, 2008:353). Of course there are sizeable minorities of young people whose lives are negatively impacted upon as a result of the perpetuation of deviance in the neighbourhood. It is therefore important to state that growing-up in an area characterized with all sorts of road and deviance culture is not just about delinquency or the effects and consequences of criminal activity, it is more about placing such adaptations and modes of being within the broader context of the young people's everyday lived experiences. Even though many of the areaboys flirt with deviant acts, they are not career criminals who have created lifestyles around deviance and hyper- masculinity as a result of social and economic marginalization. Rather, they are at a point in their lives when they are discovering who they are and what they are about as individuals in their own right; they are looking to push the boundaries of adult society and do what most normal teenagers do - rebel. As Katz (1988: 80) notes:

'in many youthful circles to be bad, to be a [badass] or otherwise overtly to embrace symbols of deviance is a good thing', especially when the symbols, styles and aesthetics of badness are celebrated within contemporary popular culture. via a plethora of bashment and hip-hop songs and videos.

Contrary to Mertonian explanations of relative deprivation which stress the mundaneness of crime, Young (2003) drawing on Katz's (1988) and other classic text within the field of cultural criminology, assert that crime, rather than being mundane, has its: excitement, its drama, its seductions and punishment, like it, its vindictiveness, its hostility, its thinly concealed satisfactions.(p. 392). Young and other writers working within the area of cultural criminology (Sanders, 2005; Gunter, 2008) maintain that the values and seductions of deviance are celebrated within popular mainstream culture; consequently acting them out behaviourally may be particularly appealing to those individuals and subcultures operating at the margins of society. Wright et al. (2006: 2), in their study that looked at the situational dynamics of street robbery in the United Kingdom, also noted that whilst offending behavior was largely motivated by a need to obtain money, it was 'activated, meditated and channelled by participation in an emerging street culture in Britain linking deviance and criminal motivation to growing up poor, in a poor neighbourhoods, subjective to situational conditions'

\section{Conclusions}

Among any deprived categories, researchers on youth and juvenile delinquencies tend to either focus on why certain youths commit crimes (Owumi, 1994; Omitoogun, 1996) - or alternatively on young males' continued oppression and criminalization by the society, police and criminal justice system (Phillips and Bowling, 2003). Within this paper I have, following Gunter's study (2008) among black deprived youths in East London focused on exploring the notion of deviance through detailing its impact and influence on the everyday lived experiences of those young street children, with difficult childhood which I termed 'growing up poor' residing in Lagos central neighbourhood. When examining the potential causes and consequences of deviance and street crime among young people - and adults - I feel it is important that such behaviours are located within the wider context of familial challenges, the residential locality and wider peer/social networks. Similarly I contend that deviance is a mode of being (or code of the street, Anderson, 1999) the young touts/areaboys themselves see as being central to Road life in Lagos Central Neighbourhood. In addition, there is a small uncompromising grouping of young males who continuously are on the verge of committing one deviant act or another. Such young males immerse themselves in deviance - via lifestyle choices based on their involvement in property offences, fraud, violent offences, street bullying and drug dealing - in order to maintain and enhance their notorious reputations within the neighbourhood.

Whilst the majority of young male with the label 'touts' involved in Road culture do not immerse themselves in deviance, as a result of 'drift' (Matza, 1964) they do nonetheless appropriate specific elements of gangster culture - or the code of the street (Anderson, 1999) - namely their involvement in: petty feuds or 'beef'; money making-schemes via fraud and the handling of stolen goods; and lastly, their adoption of aggressive street-tough personas and attitudes as a means of warding off potential male aggressors. Unfortunately, those young black males who refuse to adopt such notorious street personas are more likely to be perceived as weak and effeminate, rendering them vulnerable to verbal and physical abuse/attacks from their more dominant and street confident peers. For those unlucky street boys who subsequently find themselves caught up within the police net will, more often than not, be treated harshly by the police; this in turn may result in their becoming more harden, more committed to deviance and the notorious the street lifestyle.

Lastly, knowing that institutional reforms are relevant (as it currently going on in Fashola's government) in combating the current spate of deviance and touting in the street of Lagos Central Neighbourhood as in major cities in Nigeria, this study contends that specific reforms and innovations should be constructed within the sociological process that assist in shaping survival strategies among youths living in the margin of the city within the framework of urban development. In determining possible areas of recommendation and intervention for individuals already on the street imbibing the deviant lifestyle, this study suggests the policy framework developed for the United Nations Youth Employment Network (YEN) programmes (2002), with four thematic priorities - employability, equal opportunities, entrepreneurship and employment creation (known as the 'four Es'). The four Es, highlight youth employment, and the 
challenges associate with each, and how they can practically impact on young people seeking to make ends meet in the margin of city walls as common as most evident in the developing world.

i. Employability: government should create an environment that will improve the quality of nation's education system through investments in free technical education that will have meaningful impact on the youth and the quest for self reliance and development, a characteristic feature of the Chinese economy. In the long run this will influence and increase youths employment outcomes.

ii. Equal opportunities: It is also suggested that policies should be put in place at all level for young men and women to have the same opportunities in job prospecting. Emphasis should also be placed on vulnerable groups especially children and youths; to avoid child labour and exploitation, street life and the breeding of street urchins in cities.

iii. Employment creation: Complementary to employability, government and well to do individuals should provide equal opportunities and entrepreneurial strategies and programmes with assistance from local and international organisations to explore opportunities and in increasing the number of quality and legitimate jobs in niche industries and the informal sector.

iv. Entrepreneurship: Governmental policies should make it easier for youths to acquire soft loans through guarantors to start, own and run small scale enterprises, which will add more values to their lives and in the long run strengthening the nation's informal sector.

\section{REFERENCES}

[1] Adisa, J. (1997). Street Culture and Families in the Street. In Youth, Street Culture and Urban Violence in Africa. Institute of African Studies. Ibadan.

[2] Aderinto, A. A. (1997). Home Dissertation among Juveniles in Lagos and Ibadan Metropolis: Causes Patterns and Consequences. PhD Thesis, Department of Sociology University of Ibadan

[3] Albert, I. O. Adisa, J., Agbola, T. and Herault, G. (1994). Urban Management and Urban Violence in Africa. IFRA-Ibadan

[4] Alemika, E.E.O. (1997). Criminal Violence and Insecurity in Lagos State, Nigeria. African Peace Review Volume 1, Number 2, October: 72-95

[5] Anderson, E. (1999). Code of the Street: Decency, Violence, and the Moral Life of the Inner City. New York, London: Norton

[6] Cohen, S. (1955). Delinquent Boys: The Culture of the Gang. Chicago, IL: Chicago Free Press

[7] Connell, R.W. (1987). Gender and Power. Cambridge: Polity Press

[8] Corrigan, P. (1979). Schooling the Smash Street Kids. Lon- don: Macmillan

[9] Ferrell, J., K.J. Hayward, W. Morrison and M. Presdee (2004). Cultural Criminology Unleashed. London: Glasshouse Press

[10] Garland, J., B. Spalek and N. Chakraborti (2006). 'Hearing Lost Voices: Issues in Researching Hidden Minority Ethnic Communities', British Journal of Criminology 46: 423-37

[11] Gilroy, P. (1982). 'Police and Thieves', in The Empire Strikes Back, Birmingham

[12] Gray, O. (2003). 'Badness-Honour', in A. Harriot (ed.). Understanding Crime in Jamaica. Kingston: University West Indies Press.

[13] Gray, O. (2003). 'Badness-Honour', in A. Harriot (ed.). Understanding Crime in Jamaica. Kingston: University West Indies Press.

[14] Gunter, A. (2004). Can't Blame the Youth: An Ethnographic Study of a Black East London Neighbourhood, unpublished PhD. London: Buckinghamshire Chilterns University College/ Brunel University

[15] Gunter, A. (2008). Growing up Bad: Black Touth, 'Road' Culture and Badness in an East London Neighbourhood. Crime Media Culture 4: 349-366

[16] Hallsworth, S. (2005). Street Crime. Devon: Willan

[17] Harrington, V. and P. Mayhew (2001). 'Mobile Phone Theft', Home Office Research Study 235. London: Home Office

[18] Heap, S. (2010). Their Days are Spent in Gambling and Loafing, Pimping for Prostitutes, and Picking Pockets: Male Juvenile Delinquents on Lagos Island, 1920s-1960s. Journal of Family History. 35:48-71

[19] Iginla, S. L. (2007). Area boys' Activities: An Underground Economy Lagos State Judiciary Report Wednesday, 11 April. Lagos State Secretariat Publication

[20] Ikuomola, A.D. (2010). Touting in Lagos State Transportation Corridors. Unpublished PhD Thesis. Department of Sociology, University of Ibadan

[21] Ikuomola, A.D., Okunola R.A, and Heap, S. (2009). Historical Analysis of Touts as a Deviant Subgroup In Lagos State Nigeria. African Journal of Arts and Humanities Vol. 2 (2), Pp.49-62

[22] Isamah, A. N and Okunola, R. A. (1997). Family Life Under Economic Adjustment: The Rise of Child Breadwinners. In Guyer, J. I. Denzer, L. Agbage A. (Eds)., Money Struggles and city life. Devaluation in Ibadan and other Urban Centres in Southern Nigeria 1986-1996. Heinemann, Portsmouth NH, Pp. 63-72.

[23] Katz, J. (1988). Seductions of Crime: Moral and Sensual Attractions in Doing Evil. New York: Basic Books

[24] Katz, J. (1988). Seductions of Crime: Moral and Sensual Attractions in Doing Evil. New York: Basic Books

[25] Keith, M. (1993). Race, Riots and Policing. London: UCL Press

[26] Lea, J. and J. Young (1984). What is to be done about Law and Order? Harmondsworth: Penguin. London Evening Standard (2002). 27 June 
[27] Matza, D. (1964). Delinquency and Drift. New York: Wiley

[28] Okojie, C.E.E. (2003). Employment Creation for Youth in Africa: The Gender Dimension. A Paper Presented to Expert Group Meeting on Jobs for Youth: National Strategies for Employment Promotion, 15-16 January. Geneva, Switzerland

[29] Okunola, R. A. (2009).Commutters' ferar of crime and the road transport industry: Astudy of Ibadan-sokoto transport Corridor. The Nigerian Journal of Sociology and Anthropology. Vol. 7:98-118

[30] Omitoogun, W. (1996). Organized Street Violence: The Area Boys of Lagos. In Urban Violence in South, West and Central Africa. Antoinette Louw and Simon Bekker. Eds. Indicator Press, Durban South Africa

[31] Owumi, B.E. (1994). New Trends and Attitudes Toward Crime: The Phenomenon of Area boys in Nigeria In Albert, I. O. Adisa, J., Agbola, T. and Herault, G. (eds). Urban Management and Urban Violence in Africa. IFRA-Ibadan. Pp. 217- 222

[32] Phillips, C. and B. Bowling (2003). 'Racism, Ethnicity and Criminology: Developing Minority Perspectives', British Journal of Criminology 43(2).: 269-90

[33] Sanders, B. (2005). Youth Crime and Youth Culture in the Inner City. London: Routledge.

[34] Sewell, T. (1997). Black Masculinities and Schooling: How
Black Boys Survive Modern Schooling. Staffordshire: Trentham

[35] Spalek, B. (2008). Communities, Identities and Crime, Bristol: Policy Press

[36] Stenson, K. and F. Factor (1994). 'Youth Work Risk and Crime Prevention', Youth and Policy 45: 1-15

[37] Stolzoff, N. (2000). Wake the Town and Tell the People: Dancehall Culture in Jamaica. Durham and London: Duke University Press

[38] The Guardian. (2009). Areaboys: Stopping the Threats to Mega City Dream. News-Feature Street Pulse. Sunday, June 21 st Pg 8

[39] United Nations Youth Employment Network (YEN) programmes (2002). Four Thematic Priorities for Youth Employment

[40] Van Deburg, W.L. (2004). Hoodlums: Black Villains and Social Bandits in American Life. London: University of Chicago Press

[41] Wright, R., F. Brookman and T. Bennett (2006). 'The Foreground Dynamics of Street Robbery in Britain', British Journal of Criminology 46: 1-15

[42] Young, J. (2003). 'Merton with Energy, Katz with Structure: The Sociology of Vindictiveness and the Criminology of Transgression', Theoretical Criminology 7: 3 